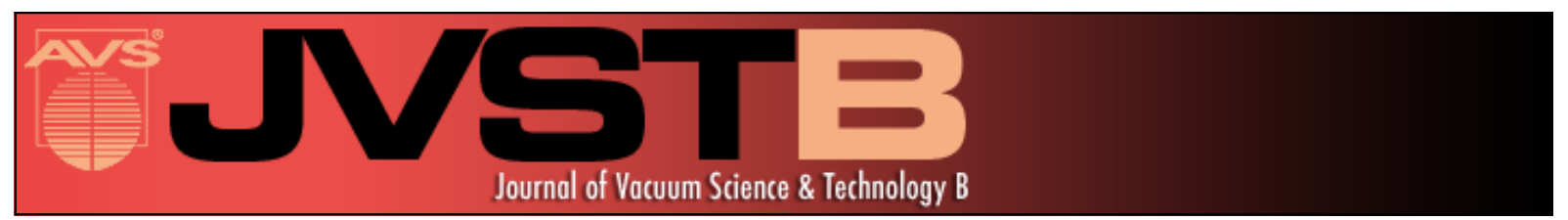

\title{
Ashing of photoresists using dielectric barrier discharge cryoplasmas
}

Sven Stauss, Shusaku Mori, Hitoshi Muneoka, Kazuo Terashima, and Francesca lacopi

Citation: Journal of Vacuum Science \& Technology B 31, 061202 (2013); doi: 10.1116/1.4825202

View online: http://dx.doi.org/10.1116/1.4825202

View Table of Contents: http://scitation.aip.org/content/avs/journal/jvstb/31/6?ver=pdfcov

Published by the AVS: Science \& Technology of Materials, Interfaces, and Processing

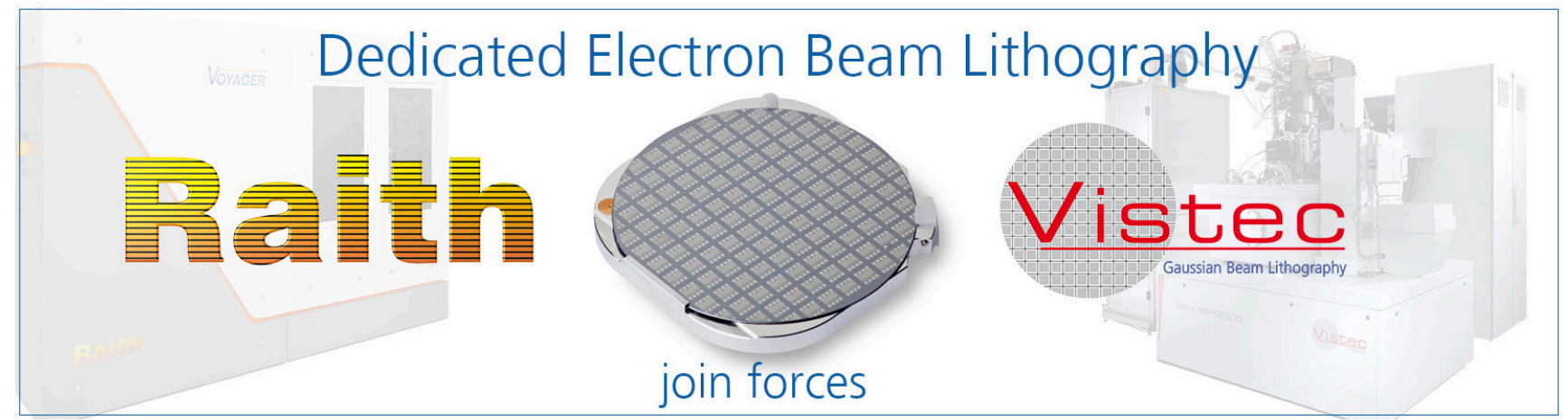




\title{
Ashing of photoresists using dielectric barrier discharge cryoplasmas
}

\author{
Sven Stauss, ${ }^{\text {a) }}$ Shusaku Mori, Hitoshi Muneoka, and Kazuo Terashima ${ }^{\text {b) }}$ \\ Department of Advanced Materials Science, Graduate School of Frontier Sciences, The University of Tokyo, \\ 5-1-5 Kashiwanoha, Kashiwa, Chiba 277-8561, Japan \\ Francesca lacopi $^{\mathrm{c})}$ \\ Queensland Micro and Nanotechnology Centre, 170 Kessels Road, Nathan 4111, Queensland, Australia
}

(Received 1 May 2013; accepted 30 September 2013; published 17 October 2013)

\begin{abstract}
Plasma ashing of photoresists is a critical step in advanced microelectronics manufacturing as it often leads to extensive damage in porous organosilicate low- $\kappa$ dielectrics and hinders the use of highly porous films in interconnects. To reduce plasma damage, the authors investigated the feasibility of ashing a 248-nm photoresist with cryoplasma. The authors ashed photoresist-coated silicon wafers with dielectric barrier discharge microplasma generated at temperatures of $170-291 \mathrm{~K}$, a pressure of 100 Torr, applied voltages of $V_{\text {appl }}=0.8-1.6 \mathrm{kV}$, and a frequency of $f=20 \mathrm{kHz}$ in both $\mathrm{Ar} / \mathrm{O}_{2}$ and $\mathrm{Ar} / \mathrm{O}_{2} / \mathrm{N}_{2}$ gas mixtures. While the ashing rates at $170 \mathrm{~K}$ in $\mathrm{Ar} / \mathrm{O}_{2}$ decreased to about $20 \%$ of the ashing rates achieved at room temperature and $240 \mathrm{~K}$, the addition of $\mathrm{N}_{2}$ to the plasma gas enhanced the ashing rates by a factor of 1.5-2. Optical emission spectroscopy measurements of the plasmas showed that, in the $\mathrm{Ar} / \mathrm{O}_{2} / \mathrm{N}_{2}$ mixture, the main reactive species are $\mathrm{N}_{2}$ radicals; $\mathrm{x}$-ray photoelectron spectra of the ashed photoresists indicated that ashing is initiated from oxygen-containing functional groups of the photoresist. This study showed that decreased ashing rates at low plasma gas temperatures can be significantly enhanced by adjusting the plasma chemistry and that cryoplasma offers a viable process to minimize the damage from ashing of low- $\kappa$ dielectric materials in interconnects, which will allow nanoelectronic devices to fully benefit from the introduction of such porous materials. (C) 2013 American Vacuum Society. [http://dx.doi.org/10.1116/1.4825202]
\end{abstract}

\section{INTRODUCTION}

Producing nanoelectronic devices containing characteristic features with sizes that approach the dimensions of a few nanometers presents new challenges and issues for different fields. These challenges include the development and choice of novel materials and the establishment and optimization of new and existing processing methods and equipment. Currently, one of the main problems encountered in transistors, which are approaching technology nodes in the range of $10 \mathrm{~nm}$, is the influence of cross-talk and current losses. Alternative low- $\kappa$ dielectric materials ${ }^{1}$ such as porous organosilicate glasses (OSGs) have shown the promise of being able to address these problems. ${ }^{2}$ In such low- $\kappa$ or ultralow- $\kappa$ dielectrics, the low dielectric constant $\kappa$ is achieved by incorporating covalently bonded $-\mathrm{CH}_{3}$ groups into the $\mathrm{SiO}_{2}$ lattice. ${ }^{3}$ The $\kappa$ values of such OSG materials can be further reduced by introducing a network of mesopores. One crucial step in the patterning of low- $\kappa$ dielectrics is the removal or ashing of the photoresist, because typical ashing processes of low- $\kappa$ (Ref. 4) and ultralow- $\kappa$ (Refs. 3 and 5) dielectric materials by reactive ion etching introduce extensive plasma damage to the dielectric, which increases the effective $\kappa$ value. ${ }^{6}$ The resulting detrimental increase in $\kappa$ is dramatically amplified as feature sizes scale down in advanced interconnects and is mainly caused by two concomitant mechanisms:

\footnotetext{
${ }^{a)}$ Electronic mail: sven.stauss@plasma.k.u-tokyo.ac.jp

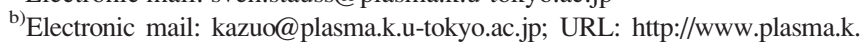
u-tokyo.ac.jp

${ }^{c}$ Electronic mail: f.iacopi@griffith.edu.au
}

(1) Covalent $-\mathrm{CH}_{3}$ groups are removed from the pore surface by oxygen radicals, and ultraviolet (UV) and vacuum ultraviolet (VUV) irradiation produced by the ashing plasma, leaving the material highly hydrophilic.

(2) The dangling bonds left on the surface of the pores either attach to moisture present in the atmosphere or undergo a cross-linking process leading to a net reduction in the porous volume of the film.

In recent years, many studies have been conducted to understand the chemical modification and degradation of OSG films during plasma more in detail. The modifications are mainly caused by oxygen radicals, which diffuse into the pores, but also UV and VUV photons that can penetrate into OSG films. The penetration depth of plasma species and photons and the resulting damage depends on many factors, e.g., the background pressure, plasma gas composition, and generating conditions (e.g., plasma power and substrate bias), and the composition and morphology of the OSG films. ${ }^{7}$ Recent experimental ${ }^{8,9}$ and numerical studies ${ }^{10}$ of plasma processing of OSGs also investigated more in detail the separate influence of oxygen radicals and VUV photons. It was found that especially VUV irradiation can lead to direct scission of Si-C and $\mathrm{Si}-\mathrm{O}$ bonds, which accelerates the removal of $-\mathrm{CH}_{3}$ groups, therefore enhancing damage by oxygen radicals and leading to an increase of $\kappa \cdot{ }^{9}$ On the other hand, ions have shown to lead to a densification of OSG films, which can mitigate the damaging effect of oxygen radicals, ${ }^{8}$ and the effect of oxygen and hydrogen radicals on the OSG can also be reduced to a certain extent by 
organic cross-linking. ${ }^{11}$ The ab-initio molecular dynamic simulations conducted in this study showed that in such modified OSG films, oxygen radicals preferentially break $-\mathrm{Si}-\mathrm{CH}_{2}-\mathrm{Si}$ instead of $\mathrm{Si}-\mathrm{CH}_{3}$ bonds, thereby limiting carbon removal.

As briefly mentioned above, plasma exposure of OSG films can lead to modification of the chemistry and morphology of OSG films, resulting in an increase of the dielectric constant. To mitigate these problems, several approaches have been investigated. One is using different plasma gas chemistries to limit the low- $\kappa$ dielectric damage due to photoresist ashing by remote $\mathrm{H}_{2}$ plasmas ${ }^{12,13}$ or different combinations of Ar- and $\mathrm{N}_{2}$-containing plasmas. ${ }^{14}$ The effect of adding $\mathrm{N}_{2}$ in low- $\kappa$ etching and photoresist ashing using microwave plasmas was found to lead to reduced etching damage $^{15}$ and an increase in atomic oxygen for increased ashing rates. ${ }^{16}$ However, while changing the plasma chemistry can help alleviate the damage in low- $\kappa$ ashing to a certain extent, the plasma ashing process still leads to a modification of the composition and morphology of the top-most layers in the OSG. Therefore, a totally different approach is urgently needed to manufacture advanced interconnects with highly porous dielectric films.

Recently, cryoplasmas have been proposed as a new type of low-temperature nonequilibrium plasma that allow the plasma gas temperature to be controlled to values below room temperature. ${ }^{17}$ So far, both jet-type ${ }^{18}$ and parallel plate dielectric barrier discharge (DBD) cryoplasmas ${ }^{19}$ have been investigated down to temperatures of $4.2 \mathrm{~K}$ in He. The presence of dielectric barriers allows the current in the discharge to be limited and therefore prevents the temperature from increasing. ${ }^{20}$ Owing to the small characteristic size (electrode gap or capillary diameter) of the microplasmas and the resulting small plasma volumes, gas heating due to plasma can be neglected. ${ }^{17}$

In a recent study, we demonstrated that cryoplasma ashing of photopolymers is a promising approach for reducing damage in low- $\kappa$ OSGs. ${ }^{21}$ We generated DBD cryoplasmas in $\mathrm{Ar} / \mathrm{O}_{2}$ and compared the ashing at room temperature. The results clearly showed that the extent of ashing damage at $200 \mathrm{~K}$ was three times smaller than that at room temperature and was confined to a nanometer-thick layer close to the top surface of the dielectric. The penetration of radicals through the pore network was dramatically reduced for plasma processes below room temperature, thanks to the increase in surface sticking and recombination coefficients of the plasma radicals at cryogenic temperatures. However, while cryoplasmas reduce ashing damage in OSG, a more detailed understanding of the feasibility of photoresist ashing at cryogenic ashing temperatures, especially its efficiency, is necessary.

In order to investigate the ashing efficiency of cryoplasmas, we ashed $\mathrm{Si}$ wafers coated with an environmentally stable chemical amplification positive (ESCAP) photoresist ${ }^{22}$ using DBD cryoplasmas at ashing temperatures $\left(T_{\text {ash }}\right)$ of $170-290 \mathrm{~K}$ in $\mathrm{Ar} / \mathrm{O}_{2}$ and $\mathrm{Ar} / \mathrm{O}_{2} / \mathrm{N}_{2}$ gas mixtures. Both the plasma properties and chemical composition of the photoresist after ashing were assessed.

\section{EXPERIMENTAL APPROACH}

The experimental setup was the same as that used in the previous study ${ }^{21}$ and is shown in Fig. 1. The custom-made chamber [cf. Fig. 1(a)] comprises an inner compartment into which the electrode is placed and an outer compartment that is evacuated to maintain the inner compartment in an (a) Function

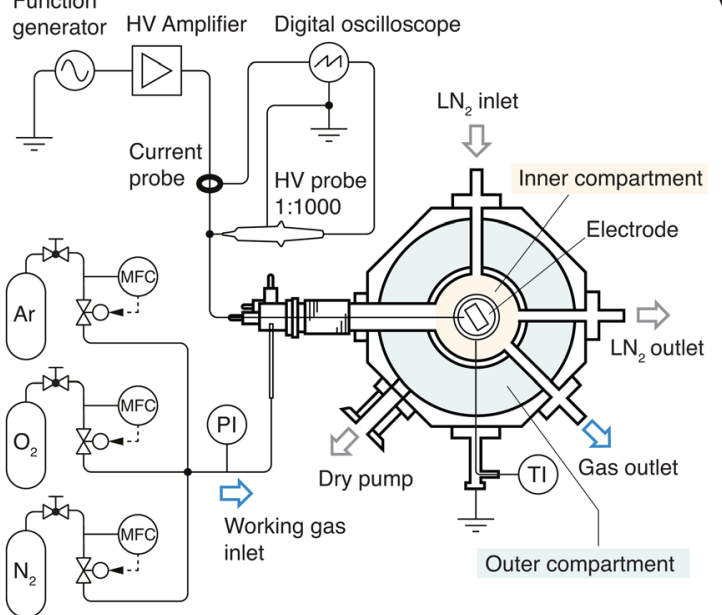

(b)

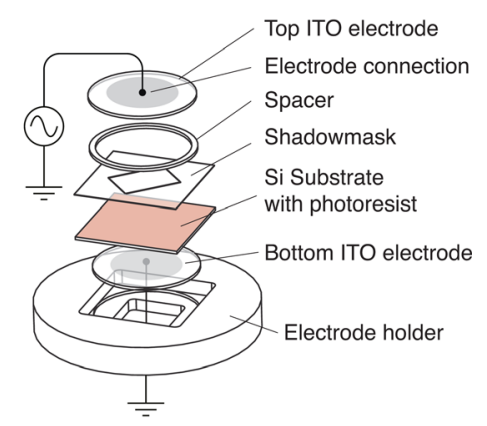

FIG. 1. (Color online) Schematic of experimental setup and electrode. (a) The cryochamber consists of an outer compartment (blue) that can be evacuated to insulate the inner compartment (red)5 adiabatically from the environment. The gas of the inner compartment is cooled by liquid nitrogen ( $\left.\mathrm{LN}_{2}\right)$ flowing through a loop. The concentrations of the plasma gases $\mathrm{Ar}, \mathrm{O}_{2}$, and $\mathrm{N}_{2}$ are controlled by mass flow controllers (MFC), while the conditions inside the chamber are monitored by pressure and temperature indicators (PI and TI). (b) The microplasma reactor consists of two ITO-covered quartz substrates (thickness of $0.8 \mathrm{~mm}$ ), a glass slide (thickness of $0.12-0.17 \mathrm{~mm}$ ) that serves as a shadow mask, and the sample, which is a photoresist-covered Si substrate (thickness of $0.5 \mathrm{~mm}$ ). To facilitate alignment of the electrode, shadow mask, and substrate, the parts are placed in a custom-made holder and pressed together (the upper part of the holder is not shown). Plasma is generated using a function generator and high-voltage power supply and characterized by current-voltage and optical emission spectroscopy measurements. The optical emission spectra are acquired by placing an optical fiber coupled to a spectrograph on top of the viewport of the cryochamber (not shown in the figure). 
adiabatic state. The DBD electrode [cf. Fig. 1(b)] was fabricated using indium-tin-oxide (ITO)-coated (nominal thickness of $0.14 \mu \mathrm{m}$, nominal sheet resistance of $10 \Omega \square^{-1}$ ) quartz disks with a diameter of $20 \mathrm{~mm}$ and thickness of $0.7 \mathrm{~mm}$. The electric connections to the electrodes were fabricated from silver conductive paste, and the shadow masks were fabricated using glass slides (thickness of $0.12-0.17 \mathrm{~mm}$ ). The shape and size of the mask (opening of $7 \times 10 \mathrm{~mm}^{2}$ ) were realized using a photomask (RapidMask, IKONICS Corp.) and abrasive etching. We used a ring fabricated out of machinable glass-ceramic (Macor ${ }^{\mathbb{B}}$, Ishihara Yakuhin Corp.) with a diameter of $20 \mathrm{~mm}$ and thickness of $0.50 \pm 0.05 \mathrm{~mm}$ as a spacer between the shadow mask and upper electrode. For samples, we used silicon substrates coated with an ESCAP photoresist (nominal thickness of $400 \mathrm{~nm}$ ) that is typically used in 248-nm UV lithography. Once the sample and electrode were placed inside the cryochamber, the inner and outer compartments of the cryochamber were evacuated to base pressures of $6.0-9.0 \times 10^{3}$ and $2.0-9.0 \times 10^{-2}$ Torr, respectively, by a dry pump (adixen Alcatel Drytel 1025, Pfeiffer Vacuum Technology AG). Ashing gases were then introduced into the chamber by mass flow controllers (MKS Instruments, Inc.) so that the pressure in the inner compartment reached 100 Torr.

Previously, a high photoresist ashing rate and low ashing damage was realized in an argon $(\mathrm{Ar})$-oxygen $\left(\mathrm{O}_{2}\right)$-nitrogen $\left(\mathrm{N}_{2}\right)$ gas mixture at a flow ratio of $\mathrm{O}_{2} /\left(\mathrm{N}_{2}+\mathrm{O}_{2}\right)=0.1{ }^{23} \mathrm{In}$ this study, we investigated the effect of two gas mixtures, $\mathrm{Ar} / \mathrm{O}_{2}$ and $\mathrm{ArO}_{2} \mathrm{~N}_{2}$, on the ashing of a photoresist at temperatures below room temperature. Once the gas flow was stabilized (after about $20 \mathrm{~min}$ ), DBD cryoplasmas were generated by applying sinusoidal waveforms with voltage amplitudes $\left(V_{\text {appl }}\right)$ that varied from 0.9 to $1.8 \mathrm{kV}$, at a frequency of $f=20 \mathrm{kHz}$. Photoresist samples were ashed for 5-80 min (the detailed experimental conditions are listed in Table I).

The optical emission (OE) spectra were recorded using an intensified charge-coupled device camera (PI-MAX2, Princeton Instruments Inc.) mounted on a Czerny-Turner monochromator (SpectraPro-500i SP-556, Acton Research Corporation) with a focal length of $500 \mathrm{~mm}$ using a grating with 300 grooves $/ \mathrm{mm}$ and a 500-nm blaze. Current-voltage curves were acquired with an oscilloscope (DSO5052A,

TABLE I. Experimental conditions adopted for ashing experiments.

\begin{tabular}{lcc}
\hline \hline Parameters & & Values \\
\hline Ashing temperature & $T_{\text {ash }}$ & $170,240,281 / 291 \mathrm{~K}$ \\
Ashing times & $t_{\text {ash }}$ & $5^{\mathrm{a}}, 10^{\mathrm{a}}, 20^{\mathrm{a}, \mathrm{b}}, 40^{\mathrm{a}, \mathrm{b}}, 70^{\mathrm{a}}, 80^{\mathrm{b}} \mathrm{min}$ \\
Applied voltage & $V_{\text {appl }}$ & $0.8-1.6 \mathrm{kV}$ \\
Applied frequency & $f$ & $20 \mathrm{kHz}$ \\
Gas flow rates (mixture 1) & $q(\mathrm{Ar})$ & $100 \mathrm{sccm}$ \\
& $q\left(\mathrm{O}_{2}\right)$ & $10 \mathrm{sccm}$ \\
Gas flow rates (mixture 2) & $q(\mathrm{Ar})$ & $98 \mathrm{sccm}$ \\
& $q\left(\mathrm{O}_{2}\right)$ & $9.9 \pm 0.1 \mathrm{sccm}$ \\
& $q\left(\mathrm{~N}_{2}\right)$ & $90 \pm 1 \mathrm{sccm}$ \\
\hline \hline
\end{tabular}

${ }^{\mathrm{a}}$ The respective ashing times for the gas mixture $\mathrm{Ar} / \mathrm{O}_{2}$.

${ }^{\mathrm{b}}$ The respective ashing times for the gas mixture $\mathrm{Ar} / \mathrm{O}_{2} / \mathrm{N}_{2}$.
Agilent Inc.) using a $1 \mathrm{kV}$ high voltage probe (P3000, Tektronix Inc.) and a current probe (TCP312, Tektronix Inc.). The discharge current $\left(I_{\mathrm{d}}\right)$ was subtracted from the total measured current $\left(I_{\mathrm{m}}\right)$ under the assumption of an equivalent circuit for the dielectric barrier electrode identical to that described in Ref. 24. Following this approach, $I_{\mathrm{d}}$ can be expressed as a function of $I_{\mathrm{m}}$ and the first derivative of $V_{\text {appl }}$

$$
I_{\mathrm{d}}(t)=\left(1+\frac{C_{\mathrm{g}}}{C_{\mathrm{sd}}}\right) I_{\mathrm{m}}(t)-\left(C_{\mathrm{g}}+C_{\mathrm{p}}+\frac{C_{\mathrm{g}} C_{\mathrm{p}}}{C_{\mathrm{sd}}}\right) \frac{\mathrm{d} V_{\mathrm{appl}}(t)}{\mathrm{d} t}
$$

where $C_{\mathrm{p}}$ is a parasitic capacitance and $C_{\mathrm{g}}=\varepsilon_{0} \varepsilon_{\mathrm{r}} A_{\mathrm{g}} g^{-1}$ is the equivalent capacitance of the gas; $A_{\mathrm{g}}$ is the active discharge area, and $g \sim 380-400 \mu \mathrm{m}$ is the discharge gap. In our case, the active discharge area defined by the shadow mask was $7 \times 10 \mathrm{~mm}^{2}$. The equivalent capacitance of the two dielectric disks was estimated from $C_{\mathrm{sd}}=\frac{1}{2} \varepsilon_{0} \varepsilon_{\mathrm{r}} A_{\mathrm{sd}} h^{-1}$, where $A_{\mathrm{sd}}$ and $h=0.7 \mathrm{~mm}$ were the area and thickness of the dielectric, and $\varepsilon_{0}$ and $\varepsilon_{\mathrm{r}}$ are the vacuum and relative permittivities, respectively. When $\varepsilon_{\mathrm{r}}=4.43$ for quartz and $\varepsilon_{\mathrm{r}} \sim 1$ for $\mathrm{He}, C_{\mathrm{g}}=3.0 \pm 0.8 \mathrm{pF}$ and $C_{\mathrm{sd}}=8.80 \pm 0.03 \mathrm{pF}$, respectively. To reduce the noise when calculating the numerical derivative $\mathrm{d} V_{\text {appl }}(t) / \mathrm{d} t$ in Eq. (1), we used a global regularization method ${ }^{25}$ with the regularization parameter $\lambda=50$. The parasitic capacitance $C_{\mathrm{p}}$ was estimated from

$$
C_{\mathrm{p}}(t)=\left(\frac{\mathrm{d} V_{\mathrm{appl}}(t)}{\mathrm{d} t}\right)^{-1} I_{\mathrm{m}}(t)-\frac{C_{\mathrm{sd}} C_{\mathrm{g}}}{C_{\mathrm{sd}}+C_{\mathrm{g}}}
$$

in the time region before plasma generation. $C_{\mathrm{p}}$ was found to not be constant for all experiments; this was assumed to have been caused by variations in the sizes of the active electrode area and attachments of the wire contacts on the ITO using silver paste. To calculate the discharge current $I_{\mathrm{d}}, C_{\mathrm{p}}$ values of $\sim 35 \pm 2 \mathrm{pF}$ and $\sim 1400 \pm 100 \mathrm{pF}$ were used. The power consumption of the plasmas was estimated from the $I-V$ curves according to the following relation:

$$
P=\frac{1}{t_{1}-t_{0}} \int_{t_{0}}^{t_{1}} I_{\mathrm{d}}(t) V(t) \mathrm{d} t
$$

where $t_{0}$ and $t_{1}$ are the start and end times in a cycle.

In order to quantify the ashing rates and determine the influence of plasma conditions on the photoresist during ashing, X-ray photoelectron spectroscopy (XPS) analysis was carried out using an ESCA 850 spectrometer (Shimadzu Corp.) with $\mathrm{Mg}-\mathrm{K}_{\alpha}(1253.6 \mathrm{eV})$ irradiation. We used a general-purpose XPS analysis software to analyze the data of the XPS spectra. ${ }^{26}$ To investigate the effect of the gas composition and plasma gas temperature on the photoresist, the XPS scan of the C 1 s peak at $285 \mathrm{eV}$ was examined in more detail. To determine the number of peaks in the $\mathrm{C} 1 \mathrm{~s}$ spectra that could be resolved by XPS, we performed a semiblind deconvolution of the $\mathrm{C}$ 1s peak using Tikhonov regularization; ${ }^{27}$ we assumed an instrumental broadening function 
having a Gaussian peak shape with an FWHM of $\sim 1.5 \mathrm{eV}$. Based on the number of resolved XPS peaks, we employed a model that considers the chemical bonding in the ESCAP photoresist to reproduce the change in composition during ashing.

\section{RESULTS AND DISCUSSION}

\section{A. I-V characterization of ashing cryoplasmas}

Figure 2 presents two photographs of the DBD cryoplasmas during photoresist ashing at $170 \mathrm{~K}$ in the $\mathrm{Ar} / \mathrm{O}_{2}$ [Fig. 2(a)] and $\mathrm{Ar} / \mathrm{O}_{2} / \mathrm{N}_{2}$ mixtures [Fig. 2(b)]. In both cases, the discharges appeared uniform except for near the edges of the shadow mask. The breakdown voltages for both gases were about the same at $0.7 \pm 0.2 \mathrm{kV}$ for $\mathrm{Ar} / \mathrm{O}_{2}$ and $0.7 \pm 0.1 \mathrm{kV}$ for the $\mathrm{Ar} / \mathrm{O}_{2} / \mathrm{N}_{2}$ mixture. However, igniting the discharge for the $\mathrm{Ar} / \mathrm{O}_{2}$ gas was more difficult. After the breakdown conditions were reached, the applied voltage was increased until the discharge appeared uniform. For the $\mathrm{Ar} / \mathrm{O}_{2}$ gas mixture, the applied voltage during ashing varied from $0.91 \mathrm{kV}$ to $1.14 \mathrm{kV}$, while $V_{\text {appl }}$ was set to $1.6-1.8 \mathrm{kV}$ for the mixture including $\mathrm{N}_{2}$. The power consumption estimated from Eq. (3) yielded values of $0.32-0.40 \mathrm{~W}$ for the $\mathrm{Ar} / \mathrm{O}_{2}$ plasma and $1.05-1.43 \mathrm{~W}$ for the $\mathrm{Ar} / \mathrm{O}_{2} / \mathrm{N}_{2}$ plasma.

Figure 2(c) shows an example of $I-V$ curves acquired during ashing in $\mathrm{Ar} / \mathrm{O}_{2}$ at $170 \mathrm{~K}$. The graph shows the variation in $I_{\mathrm{d}}$ estimated from $V_{\text {appl }}$ and $I_{\mathrm{m}}$ according to Eq. (1). $I_{\mathrm{d}}$ increased when $V_{\text {appl }}$ reached a threshold level of about $0.2-0.4 \mathrm{kV}$ in both positive and negative half-cycles. When observed visually, the discharge appeared uniform; however, both of the $I_{\mathrm{m}}$ and $I_{\mathrm{d}}$ waveforms contained small current spikes in both the positive and negative half-cycles. The widths of these current spikes were about 50-10 ns. Such discharge behavior is characteristic of filamentary DBDs. ${ }^{28}$

The transition from glow discharge to filamentary discharges in DBDs depends on many different factors and has been studied in detail previously. ${ }^{29,30}$ Besides the electrode geometry, particularly the gap distance, these include the driving voltage, frequency, and plasma chemistry. In principle, lower $\mathrm{O}_{2}$ content in the range of $0.3-0.6$ vol. \% has been reported to allow the generation of glow discharge. ${ }^{31}$ Here, the $\mathrm{O}_{2} / \mathrm{Ar}$ ratio was $10 \%$, which might explain why it was not possible to obtain a glowlike discharge.

For the $\mathrm{Ar} / \mathrm{O}_{2} / \mathrm{N}_{2}$ gas mixture at $170 \mathrm{~K}$ [shown in Fig. 2(d)], the current waveforms did not contain as many sharp current peaks as in the case of the $\mathrm{Ar} / \mathrm{O}_{2}$ gas. The $I_{\mathrm{d}}$ curves contained a single broad peak with a duration of $\sim 10 \mu$ s in both the positive and negative half-cycles onto which smaller current peaks were superimposed. This suggests that, while the presence of $\mathrm{N}_{2}$ leads to a reduction of Ar radicals and atomic oxygen, it also assists in obtaining a more uniform glowlike discharge.

\section{B. Optical emission spectroscopy of cryoplasmas}

As shown in Fig. 2, in both cases, the plasma emission had a blue purplelike color; however, the addition of $\mathrm{N}_{2}$ did not lead to a striking change in the plasma appearance. To obtain a better understanding of the differences between the (a)
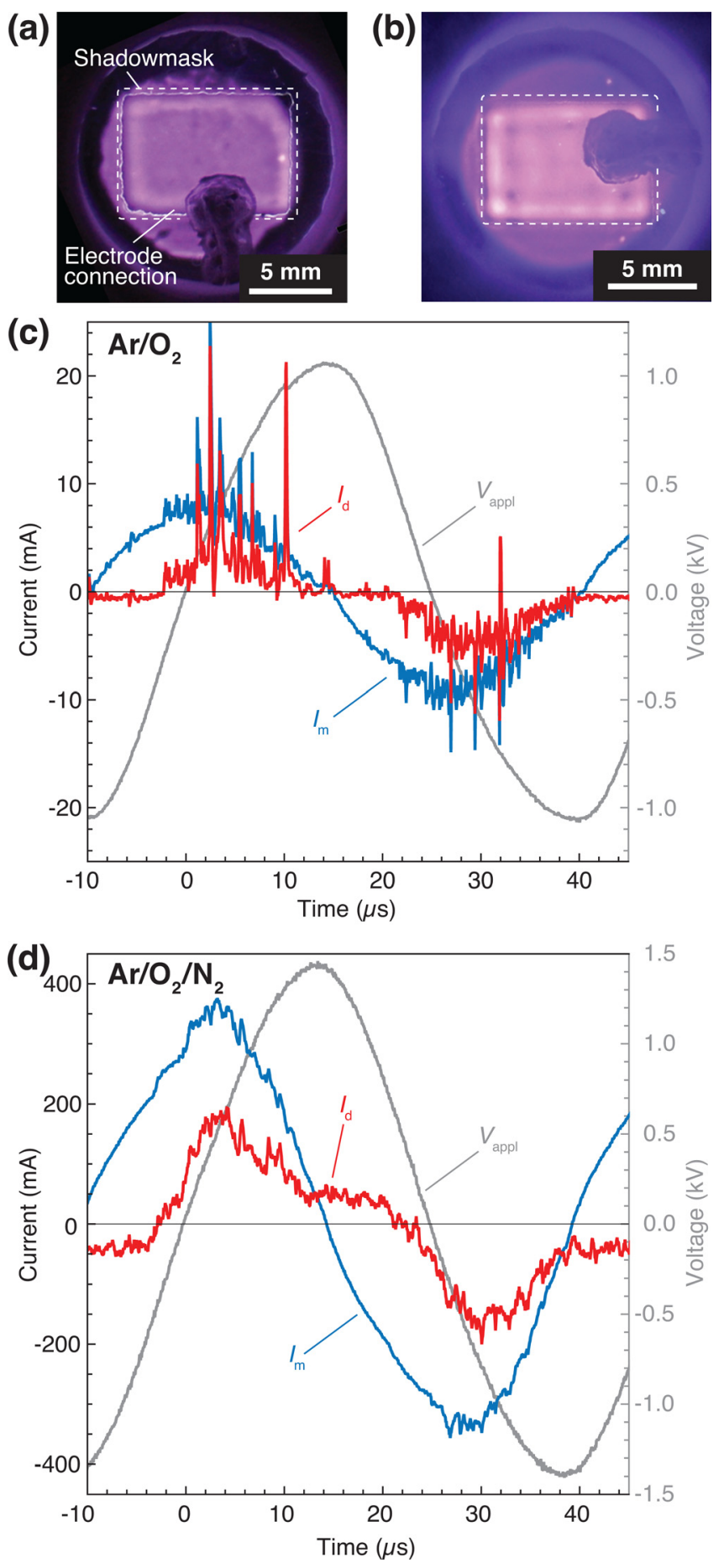

FIg. 2. (Color online) Photographs (exposure time $30 \mathrm{~s}$ ) and $I-V$ curves of plasmas during photoresist ashing. (a) $\mathrm{Ar} / \mathrm{O}_{2}$ mixture (applied voltage $V_{\text {appl }}=1.09 \mathrm{kV}, f=20 \mathrm{kHz}, T_{\text {ash }}=170 \mathrm{~K}$ ). (b) $\mathrm{Ar} / \mathrm{O}_{2} / \mathrm{N}_{2}$ mixture. Experimental conditions: $V_{\text {appl }}=1.80 \mathrm{kV}, f=20 \mathrm{kHz}, T_{\text {ash }}=170 \mathrm{~K}$. (c) Variation of $V_{\text {appl }}$; measured and discharge currents $\left(I_{\mathrm{m}}, I_{\mathrm{d}}\right)$ in the $\mathrm{Ar} / \mathrm{O}_{2}$ mixture during ashing at $170 \mathrm{~K}$. (d) Applied voltage and current waveforms of a discharge generated in $\mathrm{Ar} / \mathrm{N}_{2} / \mathrm{O}_{2}$ at $170 \mathrm{~K}$. Here, $I_{\mathrm{d}}$ shows a single large current peak onto which current spikes were superimposed.

adopted plasma conditions and their effect on the ashing of the photoresist, we acquired $\mathrm{OE}$ spectra. Two examples of OE spectra in the wavelength range of $300-850 \mathrm{~nm}$ for $T_{\text {ash }}=170 \mathrm{~K}$ for each gas mixture are shown in Figs. 3(a) and 3(b). For the $\mathrm{Ar} / \mathrm{O}_{2}$ mixture, the dominant emitting 

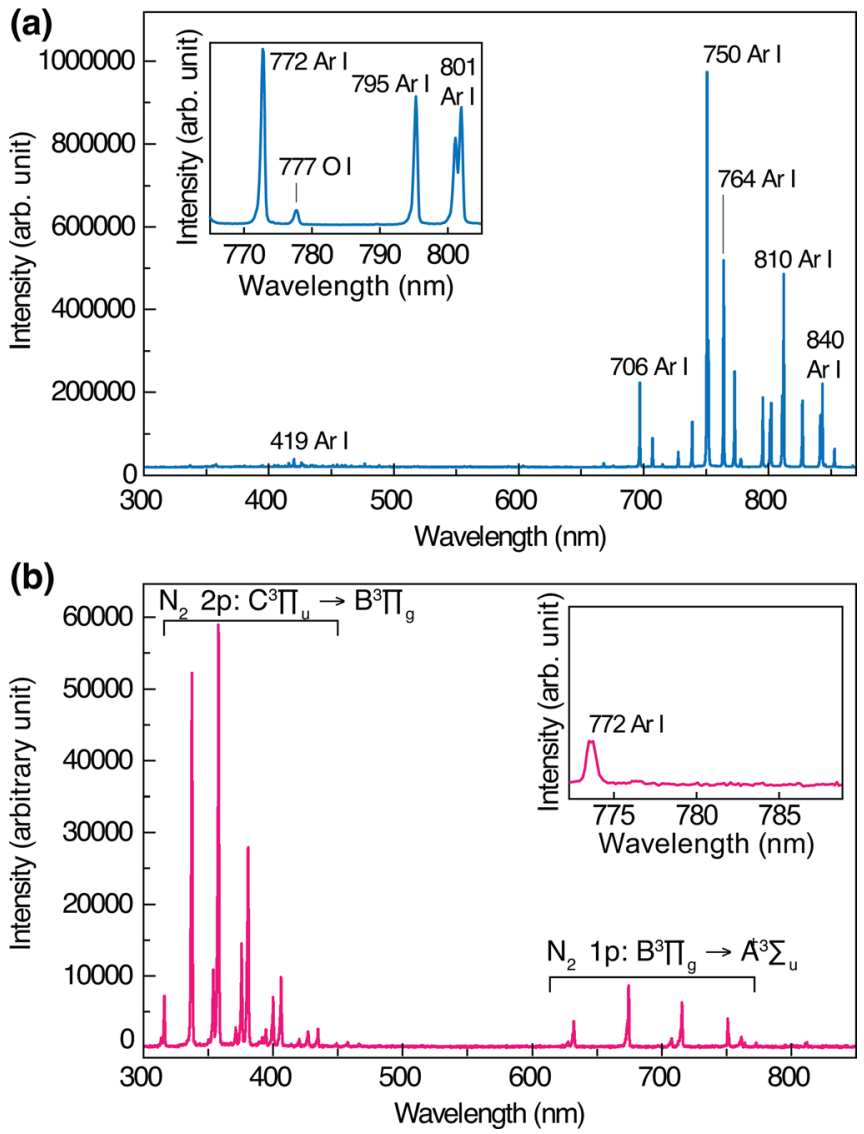

FIG. 3. (Color online) Optical emission spectra of two ashing gas mixtures at $T_{\text {ash }}=170 \mathrm{~K}$. (a) $\mathrm{Ar} / \mathrm{O}_{2}$ gas $\left(V_{\text {appl }}=1.09 \mathrm{kV}\right)$. The inset shows a detailed view of the optical emission spectrum between 765 and $805 \mathrm{~nm}$, which contains the line of atomic oxygen $(777 \mathrm{~nm})$. (b) $\mathrm{Ar} / \mathrm{O}_{2} / \mathrm{N}_{2}$ mixture $\left(V_{\text {appl }}=1.60 / 1.80 \mathrm{kV}\right)$ With the addition of nitrogen, the emission of Arexcited neutrals is greatly reduced, and molecular bands become dominant: namely, the second positive ( $\left.2 \mathrm{p}: \mathrm{C}^{3} \Pi_{\mathrm{u}} \rightarrow \mathrm{B}^{3} \Pi_{\mathrm{g}}\right)$ and first positive systems $\left(1 \mathrm{p}: \mathrm{B}^{3} \Pi_{\mathrm{g}} \rightarrow \mathrm{A}^{3} \Sigma_{\mathrm{u}}^{+}\right.$) of $\mathrm{N}_{2}$. The inset shows that, when $\mathrm{N}_{2}$ is added, the intensities of atomic oxygen emission at $777 \mathrm{~nm}$ and the Ar radicals decrease drastically.

species was $\mathrm{Ar}$ in the wavelength range of $700-850 \mathrm{~nm}$, and the small peak observed at $777 \mathrm{~nm}$ is due to atomic oxygen. For the second gas mixture that includes $\mathrm{N}_{2}$, the emission intensities of both Ar and atomic oxygen lines were greatly decreased. The dominant lines were molecular bands of $\mathrm{N}_{2}$ : those due to the second positive $\left(2 \mathrm{p}: \mathrm{C}^{3} \Pi_{\mathrm{u}} \rightarrow \mathrm{B}^{3} \Pi_{\mathrm{g}}\right)$ were between 300 and $450 \mathrm{~nm}$, and those due to the first positive systems (1p: $\left.\mathrm{B}_{\mathrm{g}}^{3} \Pi \rightarrow \mathrm{A}^{3} \Sigma_{\mathrm{u}}^{+}\right)$were in the range of $620-770 \mathrm{~nm} .{ }^{32,33}$ This indicates that, in contrast to the DBD generated in the $\mathrm{Ar} / \mathrm{O}_{2}$ gas mixture and where atomic oxygen can be considered to be the main reactive species, the reactive species leading to ashing of the photoresist in the experiments using $\mathrm{Ar} / \mathrm{O}_{2} / \mathrm{N}_{2}$ were nitrogen species. This is different from other plasma ashing processes where the addition of nitrogen was found to increase the amount of atomic oxygen. ${ }^{16}$ The amount of atomic oxygen may have been reduced here because of the low plasma gas temperature, which would lead to lower mean energies of the electrons and atomic radicals and predominant excitation of $\mathrm{N}_{2}$ molecular bands.

\section{XPS analysis}

In order to assess the effects of the different plasma conditions on the photoresist in more detail and to estimate the ashing rates, the samples were characterized by XPS. Figure 4 shows XPS spectra of selected C 1s, O 1s, and Si 2p peaks of the pristine photoresist and for films ashed for $20 \mathrm{~min}$ at $T_{\text {ash }}=240$ and $170 \mathrm{~K}$. The vertical lines in the $\mathrm{C} 1 \mathrm{~s}$ and $\mathrm{Si}$ $2 p$ spectra indicate the positions of the main components of the peaks that were used for XPS analysis and to track the variation in the $\mathrm{C}$-bonding in the photoresist film resulting from DBD cryoplasma ashing.

For C 1s, after the semiblind deconvolution, four peak components were distinguished for the nonashed sample. Since ESCAP-type photoresists are copolymers of poly $(t-$ butyl acrylate) and poly(hydroxystyrene), ${ }^{2,34}$ the peaks in the $\mathrm{C} 1 \mathrm{~s}$ spectrum correspond to $\mathrm{C}-\mathrm{C} / \mathrm{C}-\mathrm{H}, \mathrm{C}=\mathrm{O} / \mathrm{C}-\mathrm{O}-\mathrm{C}$, and $\mathrm{C}-\mathrm{OH}$ bindings (cf. molecular structure of ESCAP depicted in Fig. 6). The fourth peak is a shake-up satellite due to $\pi \rightarrow \pi^{*}$ electron transitions in the benzene ring of the 4-hydroxystyrene group of the ESCAP. ${ }^{35}$

For the nonashed sample (top curve in Fig. 4), both $\mathrm{C} 1 \mathrm{~s}$ and $\mathrm{O} 1$ s peaks were present, while the $\mathrm{Si} 2 \mathrm{p}$ signal, which can be attributed to bulk silicon $\mathrm{Si}^{0}$, is barely visible. In the case of the $\mathrm{Ar} / \mathrm{O}_{2}$ plasma gas, at an ashing temperature of $240 \mathrm{~K}$, the intensity of the $\mathrm{C} 1 \mathrm{~s}$ peak decreased, while those of the $\mathrm{O} 1 \mathrm{~s}$ and $\mathrm{Si} 2 \mathrm{p}$ peaks increased. For the Si 2p peak, the increase in the $\mathrm{Si}^{4+}$ intensity may originate from both the thermal oxide present before spin coating of the photoresist and oxidation of the substrate surface exposed to the plasma during ashing. We could not conduct angle-resolved XPS measurements; therefore, it was not possible to decouple these two possible contributions of oxygen. In contrast, at $170 \mathrm{~K}$, the peak intensities of the three investigated elements were almost the same as those of the pristine sample; this indicates that the photoresist was still intact. It also shows that this condition had low ashing efficiency.

For the $\mathrm{Ar} / \mathrm{O}_{2} / \mathrm{N}_{2}$ plasma gas, at $T_{\text {ash }}=240 \mathrm{~K}$, a similar trend as that for the $\mathrm{Ar} / \mathrm{O}_{2}$ case was observed: i.e., a marked decrease in the $\mathrm{C} 1 \mathrm{~s}$ signal while the $\mathrm{O} 1 \mathrm{~s}$ and $\mathrm{Si} 2 \mathrm{p}$ peak intensities increased. The decrease in $\mathrm{C} 1 \mathrm{~s}$ intensity was less prominent at $170 \mathrm{~K}$ compared to at $T_{\text {ash }}=240 \mathrm{~K}$. In contrast to the $\mathrm{Ar} / \mathrm{O}_{2}$ gas mixture, the increase in the $\mathrm{O} 1 \mathrm{~s}$ and $\mathrm{Si} 2 \mathrm{p}$ peak intensities indicated that the photoresist was partly removed at this temperature.

\section{Estimation of ashing rates}

In order to estimate the ashing rates as a function of the plasma gas temperature and gas mixture, the variation in atomic composition of carbon was assessed from the XPS spectra. The peak areas of the expected main contributions to the XPS signals- $\mathrm{C}, \mathrm{O}$, and $\mathrm{Si}-$ were calculated from selective scans of $\mathrm{C}$ 1s, $\mathrm{O}$ 1s, and Si 2p as presented in Fig. 4.

For the $\mathrm{Ar} / \mathrm{O}_{2}$ ashing conducted at $T_{\text {ash }}=289$ and $240 \mathrm{~K}$, the carbon content decreased to $40-50$ at. $\%$ after $t_{\text {ash }}$ $=10 \mathrm{~min}$. For the ashing conducted at $170 \mathrm{~K}$, the carbon content decreased only slightly from that in the nonashed sample of 83 at. $\%$ to approximately $78-79$ at. $\%$. However, 


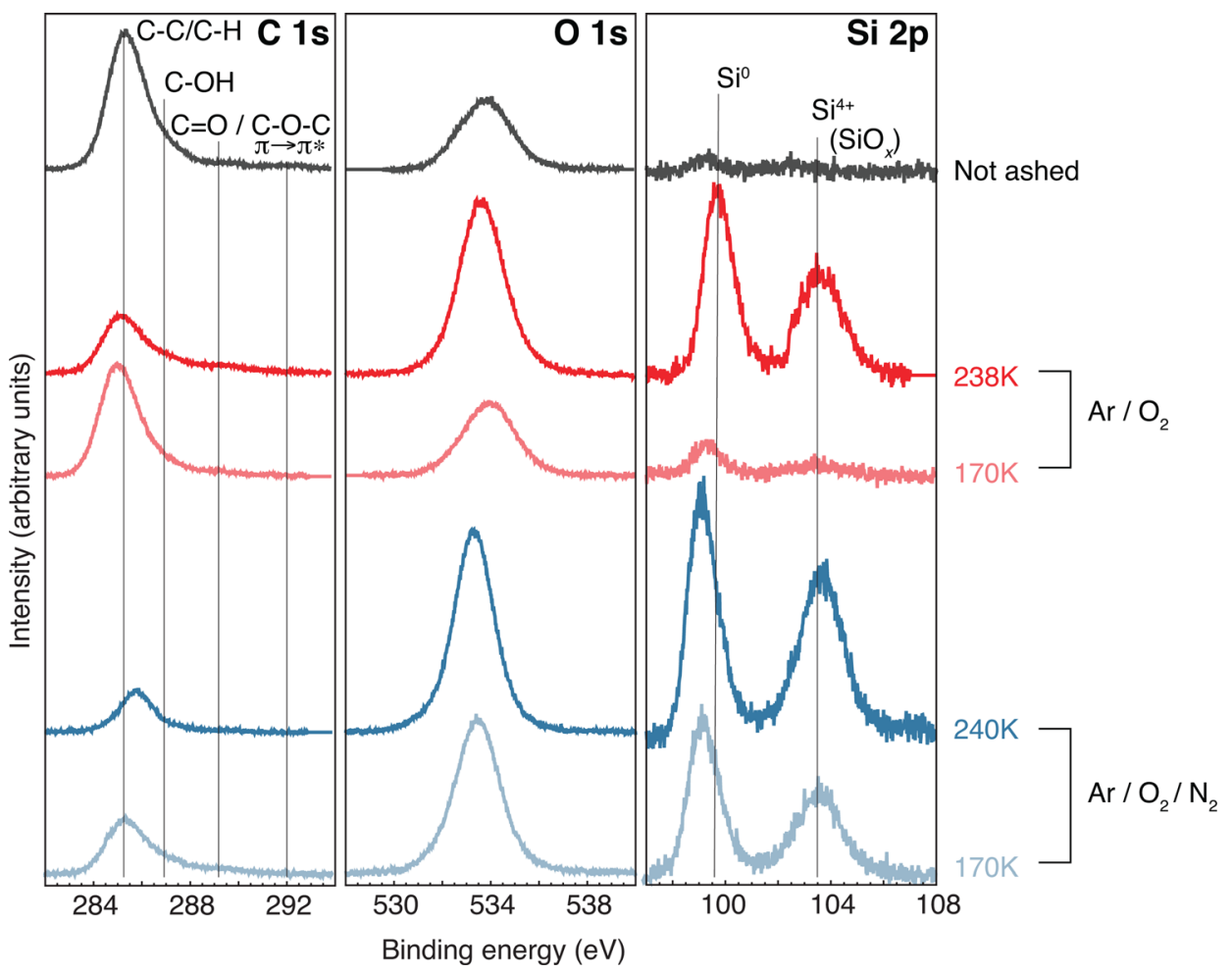

FIG. 4. (Color online) XPS spectra of C 1 s, O $1 \mathrm{~s}$ and Si $2 \mathrm{p}$ for samples ashed at $T_{\text {ash }}=240$ and $170 \mathrm{~K}$ and the $\mathrm{Ar} / \mathrm{O}_{2}$ and $\mathrm{Ar} / \mathrm{O}_{2} / \mathrm{N}_{2}$ gas mixtures. The intensities of the respective scan windows have been scaled so that they can be represented on the same graph. In the $\mathrm{C} 1 \mathrm{~s}$ and $\mathrm{Si} 2 \mathrm{p}$ windows, the lines indicate the positions of the binding energies corresponding to different chemical bonds of the components in the sample: $\mathrm{C}-\mathrm{C} / \mathrm{C}-\mathrm{H}, \mathrm{C}-\mathrm{OH}, \mathrm{C}=\mathrm{O} / \mathrm{O}-\mathrm{C}-\mathrm{O}$ a $\pi \rightarrow \pi^{*}$ shakeup satellite for $\mathrm{C} 1 \mathrm{~s}$, and two peaks that can be attributed to bulk $\mathrm{Si}\left(\mathrm{Si}^{0}\right)$ and $\mathrm{SiO}_{x}\left(\mathrm{Si}^{4+}\right)$.

for ashing durations of more than $40 \mathrm{~min}$, the C-content dropped to about 26 at. \%. In the case of the $\mathrm{Ar} / \mathrm{O}_{2} / \mathrm{N}_{2}$ gas mixture, the ashing efficiencies appeared to be slightly higher compared to $\mathrm{Ar} / \mathrm{O}_{2}$. The biggest difference between the two gas compositions was observed at $T_{\text {ash }}=170 \mathrm{~K}$, where the C-content was reduced to approximately 20 at. $\%$ after $40 \mathrm{~min}$.

The variation in the Si concentration showed the opposite trend to the $\mathrm{C} 1 \mathrm{~s}$ intensities-i.e., intensity increased depending on the ashing time. Ashing at room temperature and $240 \mathrm{~K}$ showed only a small difference in the peak intensities; at $170 \mathrm{~K}$, the intensity of the $\mathrm{Si} 2 \mathrm{p}$ peak in $\mathrm{Ar} / \mathrm{O}_{2}$ remained approximately zero for $t_{\text {ash }}$ shorter than $40 \mathrm{~min}$ before increasing, which indicates the removal of the photoresist.

In all XPS spectra, the lowest $\mathrm{C}$ concentrations did not drop to zero and only reached $\sim 18-20$ at. $\%$. The presence of residual $\mathrm{C}$ was attributed to handling of the samples after ashing; for the XPS measurements, the samples had to be transferred from the cryochamber to the chamber for XPS. This possibly led to contamination of the sample surface by the adsorption of hydrocarbons. Another reason may be the relatively high pressure of 100 Torr; some of the ashed polymer may have redeposited on the surface of the $\mathrm{Si}$ wafer. For the C $1 \mathrm{~s}$ peak intensity at $T_{\text {ash }}=170 \mathrm{~K}$ obtained for $\mathrm{Ar} / \mathrm{O}_{2}$, the carbon content was found to be constant at the beginning of the ashing process. We observed an incubation time with variable duration preceding the onset of photoresist removal. The reasons for this incubation time at $170 \mathrm{~K}$ are currently not known and will need further investigation. One reason may be residual water vapor being trapped on the top of the surface and forming a solid film at cryogenic temperature. Lower temperatures may be more prone to such an effect because of the lower energy of the plasma species.

Figure 5 shows a box plot of the ashing rates obtained from the ashing experiments in the $\mathrm{Ar} / \mathrm{O}_{2}$ and $\mathrm{Ar} / \mathrm{O}_{2} / \mathrm{N}_{2}$ gas mixtures at the three temperatures investigated. The ashing rates

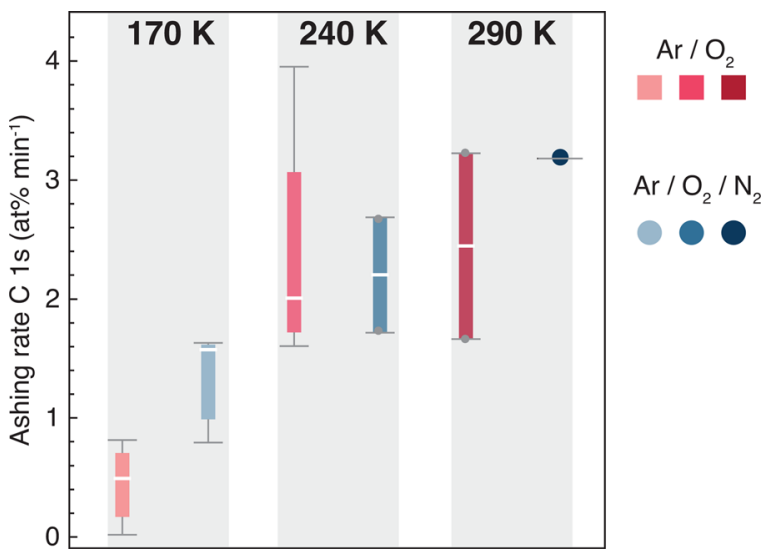

FIG. 5. (Color online) Box plot of ashing rates estimated from the variation in the C $1 \mathrm{~s}$ composition at $T_{\text {ash }}=170,240$, and $290 \mathrm{~K}$. To estimate the ashing rates, the $\mathrm{C} 1 \mathrm{~s}$ peak intensities of the individual experiments were treated as independent samples. The horizontal bar inside the boxes indicates the median value, the box boundaries are the 0.25 and 0.75 quantiles, and the horizontal bars below and above the boxes are the minimum and maximum ashing rates, respectively. 
$\left(\dot{q}_{\text {ash }}\right)$ - expressed as the variation in the carbon composition with respect to the ashing time $\dot{q}_{\text {ash }}=\Delta c_{\mathrm{C} 1 \mathrm{~s}}\left(\Delta t_{\text {ash }}\right)^{-1}$-were estimated from the change in the $\mathrm{C} 1 \mathrm{~s}$ peak intensity of the ashed and pristine samples. The horizontal bar inside the boxes in Fig. 5 are the median values, whereas the box boundaries indicate the 0.25 and 0.75 quantiles; the horizontal bars below and above the boxes are the minimum and maximum ashing rates, respectively.

The ashing rates were highest when $T_{\text {ash }}$ was close to RT $\left(\sim 2.5-3\right.$ at. $\left.\% \min ^{-1}\right)$; this was manifested by a rapid decrease in carbon content. For the samples ashed at 290 and $240 \mathrm{~K}$, the ashing rates were almost the same for both the $\operatorname{Ar} / \mathrm{O}_{2}$ and $\operatorname{Ar} / \mathrm{O}_{2} / \mathrm{N}_{2}$ gas mixtures; the median carbon content was $1.86-3.02$ at $\% \mathrm{~min}^{-1}$. When the ashing temperature was lowered to $170 \mathrm{~K}$, the median of the ashing rate dropped to $0.49 \mathrm{at} \% \mathrm{~min}^{-1}$ for the $\mathrm{Ar} / \mathrm{O}_{2}$ mixture, whereas it was $1.57 \mathrm{at} \% \mathrm{~min}^{-1}$ for the $\mathrm{Ar} / \mathrm{O}_{2} / \mathrm{N}_{2}$ gas. This could indicate that, at low ashing temperatures, the plasma chemistry may play an even more important role compared to at higher temperatures.

\section{E. Effect of cryoplasma ashing on photoresist}

In order to assess the effect of the cryoplasma ashing on the photoresist in more detail and to understand how the plasma ashing proceeds, a more detailed XPS analysis was performed. The variation of the $\mathrm{C} 1 \mathrm{~s}$ peak was fitted using a peak model that reflected the composition of a typical ESCAP photoresist. Figure 6 shows the change in individual peak components (thin black lines) and the total envelope (thick dark and thick bright lines) of the $\mathrm{C} 1 \mathrm{~s}$ peak for the $\operatorname{Ar} / \mathrm{O}_{2}$ and $\mathrm{Ar} / \mathrm{O}_{2} / \mathrm{N}_{2}$ gas mixtures when $T_{\text {ash }}=240$ and $170 \mathrm{~K}$ for pristine samples and samples ashed for $20 \mathrm{~min}$.

For the $\mathrm{C}-\mathrm{C} / \mathrm{C}-\mathrm{H}$ peak, the binding energy was set to $285.0 \mathrm{eV}$, while the $\mathrm{C}-\mathrm{OH}$ peak energy was set to $286.7 \mathrm{eV} .{ }^{36}$ In addition, a C $=\mathrm{O} / \mathrm{C}-\mathrm{O}-\mathrm{C}$ peak at $289 \mathrm{eV}$ and the shake-up satellite at $292 \mathrm{eV}$ were used for the $\mathrm{C} 1 \mathrm{~s}$ peak model. In order to keep the $\mathrm{C} 1 \mathrm{~s}$ peak model realistic, excluding the $\pi \rightarrow \pi^{*}$ shake-up satellite, the FWHM of the individual peaks was constrained to have the same value as the main $\mathrm{C} 1 \mathrm{~s}$ peak at $285.15 \mathrm{eV}$ during the fitting procedure.

In the case of $\mathrm{Ar} / \mathrm{O}_{2}$, the $\pi \rightarrow \pi^{*}$ shake-up satellite peak decreased at $T_{\text {ash }}=240 \mathrm{~K}$ compared to the intensities of the $\mathrm{C}-\mathrm{C} / \mathrm{C}-\mathrm{H}, \mathrm{C}-\mathrm{OH}$, and $\mathrm{C}=\mathrm{O} / \mathrm{C}-\mathrm{O}-\mathrm{C}$ peaks. A similar trend was observed for the $\mathrm{Ar} / \mathrm{O}_{2} / \mathrm{N}_{2}$ gas mixture; at $T_{\text {ash }}$ $=240 \mathrm{~K}$, especially, the intensity of the shake-up satellite disappeared almost completely. The decrease in the $\pi \rightarrow \pi^{*}$ peak intensity indicated that, during ashing, the hydroxystyrene groups are attacked preferentially (cf. molecular structure of ESCAP-type photoresist in Fig. 6).

Previous reports indicated that atomic oxygen is probably the main reactive species that attacks the photoresist and that the addition of $\mathrm{N}_{2}$ leads to the promotion of oxygen radicals. ${ }^{16,37}$ In the present work, we could not detect any optical emission due to atomic oxygen for the $\mathrm{Ar} / \mathrm{O}_{2} / \mathrm{N}_{2}$ mixture (cf. Fig. 3), and therefore, we assume that the contribution of $\mathrm{O}$ radicals on the ashing process is negligible. However, the emission of molecular $\mathrm{N}_{2}$ bands became dominant, and

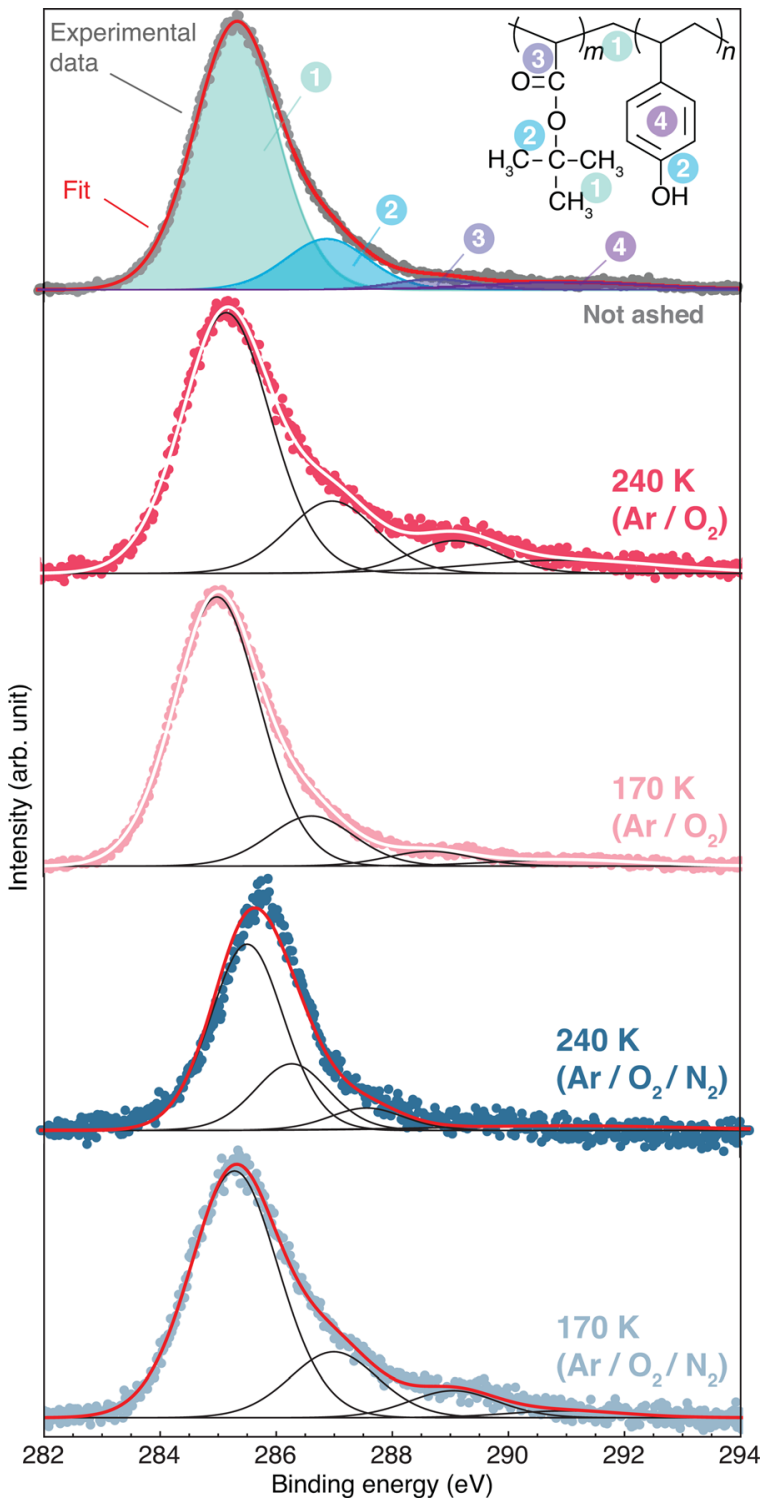

FIG. 6. (Color online) Variation of the XPS C 1s peak under different ashing conditions. The spectra were acquired for an ashing duration of $20 \mathrm{~min}$, at $T_{\text {ash }}=240$ and $170 \mathrm{~K}$, and for the $\mathrm{Ar} / \mathrm{O}_{2}$ and $\mathrm{Ar} / \mathrm{O}_{2} / \mathrm{N}_{2}$ gas mixtures to compare with the nonashed sample. To model the $\mathrm{C} 1 \mathrm{~s}$ peak, the contributions of $\mathrm{C}-\mathrm{H}$ [label (1)] and $\mathrm{C}-\mathrm{O}$ and $\mathrm{C}=\mathrm{O}$ bonding [labels (2) and (3)] that were expected to be present in an ESCAP-type monomer (cf. the inset in the nonashed XPS spectrum) were considered. Peak (4) at $291.94 \mathrm{eV}$ is a shake-up satellite that was caused by $\pi \rightarrow \pi^{*}$ valence electron transitions in the benzene rings. The black lines indicate the components of the $\mathrm{C} 1 \mathrm{~s}$ peak according to the peak model depicted for the nonashed sample, and the colored lines (white for $\mathrm{Ar} / \mathrm{O}_{2}$ and red for $\mathrm{Ar} / \mathrm{O}_{2} / \mathrm{N}_{2}$ ) indicate the envelope of the peak.

consequently, for the DBD cryoplasmas examined here, the main species promoting photoresist ashing were considered nitrogen molecular ions and radicals.

On the other hand, VUV photons have been found to enhance both $-\mathrm{SiC}$ and $-\mathrm{SiO}$ scission in the presence of oxygen radicals in plasma treatment of OSG films. ${ }^{8,9}$ Our present experimental setup did not allow the investigation of UV and VUV emission in the cryoplasmas and its effect on photoresist ashing. However, since in our previous studies, we found that the plasma emission changes as a function of 
temperature, ${ }^{19,38}$ it is assumed that the degree of VUV emission could also be controlled by the cryoplasma.

In contrast to dry ashing processes that include the use of fluorocarbon gas-e.g., $\mathrm{CF}_{4}$ - and where fluorine has been found to react with the photoresist, ${ }^{39}$ no such effect was observed in this study. Therefore, the interaction of the plasma gas species with the photoresist and incorporation of plasma species can be concluded to be negligible. However, a slight modification in the $\mathrm{C}-\mathrm{O}$ and $\mathrm{C}=\mathrm{O}$ XPS peak components due to possible air intake- e.g., during transfer of the samplescannot be completely excluded. ${ }^{40}$ Therefore, further study is necessary to obtain a more detailed understanding of the effects occurring during cryoplasma ashing. In addition, it might also be interesting to investigate the separate influence of radical species and UV or VUV irradiation during ashing of low- $\kappa$ OSG films by cyroplasmas in more detail.

\section{CONCLUSIONS}

We investigated the ashing efficiency of an ESCAP-type photoresist using DBD cryoplasmas generated at room temperature, $240 \mathrm{~K}$, and $170 \mathrm{~K}$ in both $\mathrm{Ar} / \mathrm{O}_{2}$ and $\mathrm{Ar} / \mathrm{O}_{2} / \mathrm{N}_{2}$ gas mixtures. In the $\mathrm{Ar} / \mathrm{O}_{2}$ gas, the plasmas showed $I-V$ characteristics that are typical of filamentary DBDs; for $\mathrm{Ar} / \mathrm{O}_{2} / \mathrm{N}_{2}$, the discharge current $I_{\mathrm{d}}$ behaved similarly to a glow discharge. Optical emission spectra for the $\mathrm{Ar} / \mathrm{O}_{2}$ mixture showed that the predominant species were $\mathrm{Ar}$ and atomic oxygen; for the $\mathrm{Ar} / \mathrm{O}_{2} / \mathrm{N}_{2}$ plasma, emissions due to molecular nitrogen dominated the spectra. This finding differs from those for other plasma ashing processes, where the addition of nitrogen resulted in higher production of atomic oxygen. Consequently, in the present process, the main ashing reactions were caused by reactions between nitrogen species and the components of the photoresist.

The ashing rates were estimated by analyzing the variation in atomic composition in the photoresist by XPS. Higher plasma gas temperatures led to higher ashing rates $\left(1.86-3.02\right.$ at. $\% \mathrm{~min}^{-1}$ of $\left.\mathrm{C}\right)$; ashing in $\mathrm{Ar} / \mathrm{O}_{2}$ at $170 \mathrm{~K}$ caused the mean ashing rate to drop dramatically, reaching only about 0.49 at. $\% \mathrm{~min}^{-1}$. The XPS analysis also indicated that the ashing at $170 \mathrm{~K}$ tended to have an incubation period with variable duration. The reasons for this incubation are not clear yet and need further investigation.

Adding $\mathrm{N}_{2}$ almost tripled the ashing rate at $170 \mathrm{~K}$ compared to that in the $\mathrm{Ar} / \mathrm{O}_{2}$ mixture. Thus, plasma chemistry can be concluded to be more important at lower than at higher temperatures to realizing efficient ashing rates. A detailed XPS analysis of the variation in intensities of the C $1 \mathrm{~s}$ peak components showed that the ashing proceeded first from the hydroxystyrene functional groups.

Cryoplasma ashing is expected to be a viable alternative for semiconductor processing, where the underlying layers are sensitive to plasma exposure and have to be ashed without being damaged.

\section{ACKNOWLEDGMENTS}

This work was supported by Grants-in-Aid for Scientific Research (B), Grant No. 21360356, and (A), Grant No.
24246120 from the Japan Society for the Promotion of Science. The authors thank Mitsuhiro Nakamura of the University of Tokyo for performing the XPS measurements.

${ }^{1}$ W. Volksen, R. D. Miller, and G. Dubois, Chem. Rev. 110, 56 (2010).

${ }^{2}$ K. Maex, M. R. Baklanov, D. Shamiryan, F. Iacopi, S. H. Brongersma, and Z. S. Yanovitskaya, J. Appl. Phys. 93, 8793 (2003).

${ }^{3}$ D. L. Moore et al., J. Electrochem. Soc. 152, G528 (2005).

${ }^{4}$ X. F. Hua et al., J. Vac. Sci. Technol. B 24, 1238 (2006).

${ }^{5}$ M. A. Worsley, S. F. Bent, N. C. M. Fuller, T. L. Tai, J. Doyle, M. Rothwell, and T. Dalton, J. Appl. Phys. 101, 013305 (2007).

${ }^{6}$ M. R. Baklanov, J. F. de Marneffe, D. Shamiryan, A. M. Urbanowicz, H. L. Shi, T. V. Rakhimova, H. Huang, and P. S. Ho, J. Appl. Phys. 113, 041101 (2013).

${ }^{7}$ J. Shoeb, M. M. Wang, and M. J. Kushner, J. Vac. Sci. Technol. A 30, 041303 (2012).

${ }^{8}$ H. L. Shi, H. Huang, J. J. Bao, J. J. Liu, P. S. Ho, Y. F. Zhou, J. T. Pender, M. D. Armacost, and D. Kyser, J. Vac. Sci. Technol. B 30, 011206 (2012).

${ }^{9}$ J. Lee and D. B. Graves, J. Vac. Sci. Technol. A 31, 041302 (2013).

${ }^{10}$ J. Shoeb and M. J. Kushner, J. Vac. Sci. Technol. A 30, 041304 (2012).

${ }^{11}$ M. Chaudhari and J. C. Du, J. Vac. Sci. Technol. A 30, 061302 (2012).

${ }^{12}$ O. Louveau, C. Bourlot, A. Marfoure, I. Kalinovski, J. Su, G. Hills, and D. Louis, Microelectron. Eng. 73-74, 351 (2004).

${ }^{13}$ M. S. Kuo, X. F. Hua, G. S. Oehrlein, A. Ali, P. Jiang, P. Lazzeri, and M. Anderle, J. Vac. Sci. Technol. B 28, 284 (2010).

${ }^{14}$ K. Yonekura, S. Sakamori, K. Goto, M. Matsuura, N. Fujiwara, and M. Yoneda, J. Vac. Sci. Technol. B 22, 548 (2004).

${ }^{15}$ H. W. Kim, J. H. Myung, N. H. Kim, C. W. Chung, W. J. Park, C. J. Kang, C. G. Yoo, and D. K. Choi, Vacuum 80, 193 (2005).

${ }^{16}$ K. Shinagawa, J. Yamamoto, S. Ohgawara, S. Zaima, and M. Furukawa, Jpn. J. Appl. Phys., Part 143, 6858 (2004).

${ }^{17}$ D. Ishihara, Y. Noma, S. Stauss, M. Sai, T. Tomai, and K. Terashima, Plasma Sources Sci. Technol. 17, 035008 (2008).

${ }^{18}$ Y. Noma, J. H. Choi, T. Tomai, and K. Terashima, Appl. Phys. Lett. 93, 101503 (2008).

${ }^{19}$ Y. Noma, J. H. Choi, S. Stauss, T. Tomai, and K. Terashima, Appl. Phys. Express 1, 046001 (2008).

${ }^{20}$ U. Kogelschatz, Plasma Chem. Plasma Process. 23, 1 (2003).

${ }^{21}$ F. Iacopi, J. H. Choi, K. Terashima, P. M. Rice, and G. Dubois, Phys. Chem. Chem. Phys. 13, 3634 (2011).

${ }^{22}$ H. Ito, J. Photopolym Sci. Technol. 21, 475 (2008).

${ }^{23}$ H. W. Kim et al., J. Mater. Sci. 41, 5040 (2006).

${ }^{24}$ N. Naudé, J. P. Cambronne, N. Gherardi, and F. Massines, J. Phys. D 38, 530 (2005).

${ }^{25}$ J. J. Stickel, Comput. Chem. Eng. 34, 467 (2010).

${ }^{26}$ Casa Software Ltd., see: http://www.casaxps.com (2009).

${ }^{27}$ G. M. Petrov, J. Quant. Spectrosc. Radiat. Transf. 72, 281 (2002).

${ }^{28}$ U. Kogelschatz, IEEE Trans. Plasma Sci. 30, 1400 (2002).

${ }^{29}$ N. Gherardi and F. Massines, IEEE Trans. Plasma Sci. 29, 536 (2001).

${ }^{30}$ R. Brandenburg, Z. Navratil, J. Jansky, P. St'ahel, D. Trunec, and H. E. Wagner, J. Phys. D 42, 085208 (2009).

${ }^{31}$ S. Z. Li, Q. Wu, J. L. Zhang, D. Z. Wang, and H. S. Uhm, Phys. Plasmas 17, 063506 (2010).

${ }^{32}$ A. Qayyum, S. Zeb, M. A. Naveed, N. U. Rehman, S. A. Ghauri, and M. Zakaullah, J. Quant. Spectrosc. Radiat. Transf. 107, 361 (2007).

${ }^{33}$ S. L. Fu, J. F. Chen, H. B. Zhang, C. F. Guo, W. Li, and W. F. Zhao, J. Cryst. Growth 311, 3325 (2009).

${ }^{34}$ F. Y. Tsai, S. J. Jhuo, and J. T. Lee, J. Vac. Sci. Technol. B 25, 426 (2007).

${ }^{35}$ B. D. Ratner and D. G. Castner, "Electron spectroscopy for chemical analysis," in Surface Analysis - The Principle Techniques, 2nd ed. (Wiley, New York, 2009), Chap. 3, pp. 47-112.

${ }^{36}$ A. Chilkoti, D. G. Castner, B. D. Ratner, and D. Briggs, J. Vac. Sci. Technol. A 8, 2274 (1990).

${ }^{37}$ S. B. Kim, H. Seo, J. Song, Y. Kim, H. Soh, Y. C. Kim, and H. Jeon, Jpn. J. Appl. Phys., Part 1 42, 1212 (2003).

${ }^{38}$ J. H. Choi, Y. Noma, and K. Terashima, Plasma Sources Sci. Technol. 18, 025023 (2009).

${ }^{39}$ T. Takeuchi, S. Amasaki, H. Kondo, K. Ishikawa, H. Toyoda, M. Sekine, S. Y. Kang, I. Sawada, and M. Hori, Jpn. J. Appl. Phys. 50, 08JE05 (2011).

${ }^{40}$ A. Franquet, D. Tsvetanova, T. Cunard, R. Vos, G. Vereecke, P. W. Mertens, M. M. Heyns, and W. Vandervorst, Microelectron. Eng. 88, 677 (2011). 